\title{
Differences Influence of Single Task and Dual Task on The Relationship of Increasing The Speed of The Road
}

\author{
Jasmine Kartiko Pertiwi ${ }^{*}$, Afif Ghufroni ${ }^{2}$ \\ ${ }^{1,2}$ Department of Physiotherapy, Poltekkes Kemenkes Surakarta, Indonesia \\ *Email: minemimin@yahoo.com
}

\begin{abstract}
Background: To increase of life expectancy have an affect for elderly population, is all about aging process, there will experience a setback their muscles it can be cause changes of the functional of the muscle. For example That is decrease in strength and muscle contraction, muscle elasticity and flesibility as well as speed and reaction time, as a result, the elderly will be vulnerable to falling. Objects: woman dan man elderly who have age ranges 60-74, which are included to the category of inclusion and the category of exclusion. total patients are 44 persons, they are divided into two groups. Group I are 21 subjects and Group II are 23 Subjects, the group-one subject were given single task, while the group-two subject were given dual task. Methods: this research employs two groups pre and post test design. Data analysis to find out the difference of pre and post this research employs wilcoxon test. Results: There is increase walking speed to elderly effect between pre and post in group one after 2 weeks (12 times of therapy) is $p=0.000$. The result of increase walking speed to elderly effect between pre and post in group two is $p=0.000$ and the test increase speed to elderly with ten meters walking test between group one and group two in measn group I is 3,28 and group II is 8,13. There is an difference effect of giving single task and dual task to increase walking speed to elderly. Conclusion: there is have difference in effect between the group one and group increase walking speed to elderly so that the results can be seen which is more effective is the group II with dual task.
\end{abstract}

Keyword: elderly, motoric and kognitif test, walking speed, 10MWT

\section{INTRODUCTION}

The increase in life expectancy affects the increase in the number of elderly people which results in an increase in the elderly population. In Indonesia currently experiencing a demographic bonus wherein in the pyramid of the Indonesian population aged 60 years and over widens means an increase in the elderly population, a decrease in birth rates, an increase in life expectancy, and an increase in the number of elderly people from year to year shows that the structure of Indonesia's population transitioning to an old population structure. The results of the World Population Prospect (2010) quoted from the Data and Information Center (2014) show that the life expectancy erderly in Indonesia in 2015 was $70.7 \%$, while in the world population it was $70 \%$. In 2050 it is estimated that the number of elderly people in Indonesia has reached $77 \%$, while the world population is $75.9 \%$.

Even in 2100 the number of Indonesian elderly is estimated to reach $84.5 \%$, and the world population is $81.8 \%$ (Data and Information Center, 2014). Elderly is a final stage of the human life cycle and is part of the life process that cannot be avoided and will be experienced by every individual.

Due to the aging process, various health problems will occur. Elderly will experience a setback or morphological changes in muscles that cause muscle functional changes, namely a decrease in muscle strength and contraction, muscle elasticity and flexibility, as well as speed and reaction time. 
Weakness of the lower limb muscles can cause impaired balance of the body resulting in slowness of movement, short steps, feet unable to tread strongly and late anticipate when slipping or tripping (Darmojo, 2004). Speed is a person's ability to cover a distance in the shortest possible time. Road speed in the elderly will change, among others, caused by, reduced muscle strength, reduced arm swings, body shifts, reduction in stride length (Sitompul, 2000).

Single task training is a form of exercise where the subject is given a single task such as walking, standing, and transfer (Meenakshi, 2013). The training given can be in the form of motor or cognitive tasks. Single task training is useful for improving balance, increasing motor performance, and increasing functional ability. Dual task training is an exercise in which the subject is given instructions to do 2 tasks simultaneously. Each of these tasks is referred to as a single task. Dual task training can also be used to assess cognitive levels, walking patterns, risk factors for falls and an assessment of the functional abilities of the elderly (Fadyen, 2015).

\section{METHODS}

The research design used was the Two Group Pre and Post Test Design. Group 1 was given single task training method which was done 12 times a week for 2 weeks, while group 2 was given dual task training that was done 12 times a week for 2 weeks.

This study have letter of research from Poltekkes Kemenkes Surakarta No HK 01.07/1.3/1650/2019 tgl 15 maret 2019. The research was carried out at the Dharma Bakti Nursing Home, Pajang, Laweyan, Surakarta. The study was conducted on August 19-31, 2019. The subjects according to inclusion and exclusion criteria. Measuring devices using 10MWT (10 Meter Walking Test) are carried out individually and the time is measured for $10 \mathrm{~m}$ medium to allow acceleration and deceleration. The time starts when the tip of the front foot or toe passes the 2 meter mark. Stop the time when the tip of the front foot or toe passes the 8 meter mark. Measurements on a scale of 0 to 7 . The results are said to be good if done in less than 5 minutes.

Single task training is a form of exercise with the provision of a single task to improve the ability of balance in the elderly. The tasks given in the form of (1) standing tendem with eyes closed for 30 seconds, (2) walking semitendem with eyes open as far as 3 meters, (3) walking to beside stepping the box or stool as far as 3 meters, (4) walking following the pattern provided by the therapist, 1 single task training session is done with repetition 10 times.

Dual task training is a form of speed training by giving 2 or more tasks that must be done simultaneously in the form of motor or cognitive. The form of dual task training is (1) walking semi-tendem as far as 3 meters while carrying a small ball on a plastic cup plus cognitive tasks such as memorizing words given by the therapist, (2) walking sideways stepping on the box or stool as far as 3 meters while counting backwards minus 3 of 50 , (3) subjects must draw paper with their right and left feet while mentioning words beginning with the letter ak, (4) walking along the pattern while answering simple count problems in each pattern. Each form of exercise is repeated 10 times in one session. 
The statistical analysis used to test data normality is using saphiro-test results because the number of subjects is 44 or $<50$. Before giving intervention to both groups, a homogeneity test was performed using the lavene test. Different test results from the pre and post tests use statistical tests with the Wilcoxon test.

\section{RESULTS}

1. Type of Research

a. Gender

Based on the data obtained, in both groups it was found that the number of women was greater than the group of men with the overall results are amount of male subjects is 20 people and amount of female subjects is 24 people.

b. Age

Based on the data obtained, in this age distribution, subjects were classified into 5 age groups, namely group 1 age between $60-65$ years, group 2 age 66-70 years, group 3 age 71-75 years, group 4 age $76-80$ years, and group 5 age $>80$ years. In group 1, the average subject was at age 60-65 years, while in group 2 the average age was $71-75$ years. Then in group 1 there were 1 elderly who was more than 80 years old, while in group 2 there were 5 elderly people who were more than 80 years old. This shows that the elderly who are in group 2 are older than group 1.

2. Initial State of The Subject

The results of the initial state of subjects in group 1 have an average road speed value of 27.57 while group 2 has an average of 26.52. This shows that the initial conditions of group 1 and group 2 are relatively the same or there are no significant differences.

3. Final State of The Subject

The results of the final state of the subjects in group 1 have an average road speed value of 24.28 while in group 2 have an average of 18.39. This shows that there are differences in the final results of 10MWT between groups 1 and 2.

4. Normality Test Result

Table 1. Test Data Normality

\begin{tabular}{lcc}
\hline & Shapiro Wilk Test & \\
\hline & $\boldsymbol{p}$ & Explanation \\
\hline Pre test of group I & 0,009 & abnormal \\
Pre test of group II & 0,001 & abnormal \\
\hline
\end{tabular}

Source: primery data, 2019

5. Homogeneity Test Result

Homogeneity test results in both groups obtained $p=0.607$ so that the data shows that in the two groups before treatment showed no differences or homogeneous.

6. Group 1 pre-post test different results Statistical tests in group 1 using the Wilcoxon test (2 groups in pairs) showed $\mathrm{p}<0.001$ or $\mathrm{p}<0.05$, meaning that there was an effect of treatment on increasing road speed in the elderly. So it can be concluded that there is an effect of providing single task training on increasing balance in the elderly or $\mathrm{Ha}$ is accepted.

7. Group 2 pre - post test different results 
Statistical tests in group 2 using the Wilcoxon test (2 groups in pairs) showed $\mathrm{p}<0.001$ or $\mathrm{p}<0.05$, meaning that there was an effect of treatment on increasing road speed in the elderly. So it can be concluded that there is an effect of providing dual task training on increasing speed in the elderly or Ha is accepted.

8. The results of the post test data analysis groups 1 and 2
Data analysis of the value of road speed in the elderly after treatment using the Mann Whitney test The results of the two groups after treatment obtained $\mathrm{p}=0.039$ or $\mathrm{p}<0.05$ so that there is a significant difference between group 1 and group 2 after treatment or Ha received.

9. Descriptive test results to find a better group

Table 2. Result of Mean Differences Between Both Groups

\begin{tabular}{ccccc}
\hline Group & Mean & pra-Mean & Post & Difference \\
\hline I & 27,57 & - & 24,28 & 3,28 \\
II & 26,52 & - & 18,39 & 8,13 \\
\hline
\end{tabular}

Source: primery data, 2019

\section{DISCUSSION}

Both of these exercises are proven to improve walking speed and balance, but dual task training is better at increasing speed and balance. This is in accordance with research by Konak (2016) on the effects of single-task and dual-task balance exercise programs on balance performance in adults with osteoporosis: a randomized controlled preliminary trial with 51 elderly subjects (45-88 years). From these studies it was concluded that the dual task balance exercise is more effective in increasing balance and walking speed.

The simultaneous performance of multiple tasks makes the decrease in mobility in the elderly. The dual task effect depends on the difficulty of the postural task given. There is a significant increase in the postural body when cognitive tasks are carried out in more severe postural conditions. So that older people with balance problems and a history of repetitive falls have more difficulty when perform multiple tasks. The effect of multiple tasks in postural control depends on the ability to balance the subject, the difficulty level of the balance task and the type of additional tasks performed.

In another study, it was found that the ability to do 2 activities simultaneously can be reduced due to collisions in the prefrontal cortex, but that ability can be increased again through the process of neuroplasticity of the brain. Therefore, to improve cognitive targeted neuroplasticity, specific repetition motion exercises can be a good solution. In addition, the exercise also improves coordination skills and cognitive performance in dual task exercises (Konak, 2016). 


\section{CONCLUSION}

Although single task and dual task exercises are equally effective for developing walking speed, balance and performing performance in a single task condition, dual tasks are higher than single tasks in developing walking speed and balance in the elderly. We found that participants who received the dual task exercise (either fixed or variable instruction set) showed greater progress in the speed of doing the dual task. In fact, only participants who received the dual task exercise ran faster after the exercise while doing cognitive tasks simultaneously. So, it was found a suggestion that parents can improve their work ability in dual task conditions by doing specific exercises and single task exercises might not help to control speed in walking and balance in dual task conditions.

\section{REFERENCES}

Batson, Glena. (2009). Propioception; International Association For Dance Medicine And Science.

Darmojo, R.B \& Martono, H.H. (2004). Geriatri (Ilmu kesehatan usia lanjut); Balai Penerbit FKUI, Jakarta.

Fadyen, BJ., Gagne, ME., Cossette, I., Ouellet, M.C. (2015). Using dual task walking as an aid to assess executive dysfunction ecologically in neurological populations. A narrative review; Neuropsychol Rehabil, hal 1-22.

Konak, H.E., Kibar, S., Ergin, E.S. (2016). The effect of single-task and dual-task balance exercise programs on balance performance in adults with osteoporosis: a randomized controlled preliminary trial; International Osteoporosis Foundation and National Osteoporosis Foundation.

Meenakshi, V., Sehgal, S. (2013). A comparison between single task versus dual task condition balance training in older adults with balance impairment; ISIC Institute of Health and Rehabilitation Sciences, New Delhi.

Pusat Data dan Informasi. (2014). Situasi dan Analisis Lanjut Usia; Kementrian Kesehatan RI, Jakarta Selatan.

Silsupadol, P., Chun, S.K., Shumway, C.A., Woollacott,M.H. (2006). Training of Balance Under Single and Dual-Task Conditions in Older Adults With Balance Impairment; PhysTher, vol 86, hal $269-281$.

Silsupadol, P., Shumway, C.A., Lugade, V., et al. (2008). Effects Of SingleVs. Dual-Task Training On Balance Performance Under Dual-Task Conditions In Older Adults With Balance Impairment. Department of Human Physiology, University of Oregon Libraries.

Wollesen, B., Mattes, K., Schulz, S., et al. (2017). Effects of Dual-Task Management and Resistance Training on Gait Performance in Older IndividualsA Randomized Controlled Trial. Aging Neurosci, vol 9, hal 415 